Research Article

\title{
Prevalence of G6PD deficiency versus oxidizing drugs: a survey in the tertiary care hospital
}

\author{
Rakesh R. Pathak*, Sunita B. Chhaiya, Dimple S. Mehta
}

Department of Pharmacology, C.U. Shah Medical College, Surendranagar 363001, India

Received: 10 January 2013

Accepted: 27 January 2013

\author{
*Correspondence to: \\ Dr. Rakesh R. Pathak, \\ Email: rr_pathak@yahoo.com
}

\section{(C) 2013 Pathak RR et al. This is an} open-access article distributed under the terms of the Creative Commons Attribution License, which permits unrestricted use, distribution, and reproduction in any medium, provided the original work is properly cited.

\begin{abstract}
Background: G6PD deficiency is distributed worldwide including India and is involved in accidental hemolysis and anemia by inadvertent use of oxidizing drugs. Awareness of community wise occurrence of G6PD deficiency can help in screening beforehand.

Methods: On 150 community wise classified, non-anemic, nonhemolysed (in recent past) visitors of pathological laboratory attached to C U Shah Medical College, Surendranagar, Gujarat, Crayman's hemoglobin colorimetric kit (item no 700540) was used to estimate normal or below normal status of G6PD.

Results: 10 people (6.6\% of population) were found deficient -7 (4 male +3 female) from Harijan community, 2 ( 1 male +1 female) from Rabbari community and 1 ( 1 male +0 female) from Lohana community. Conclusions: While applying oxidizing drugs in a person of Harijan community (prevalence 7 out of total 26, i.e. 27\%), extra caution is required, esp. if a person otherwise vulnerable (e.g. alcoholic). For other less represented communities, larger stratified sampling is required.
\end{abstract}

Keywords: G6PD deficiency, Oxidizing drug, Dapsone, Aspirin, Alcohol, Isoniazid

\section{INTRODUCTION}

The third world countries spend $30-40 \%$ of their total health budget on drugs, some of which are useless and expensive and double their expenditure every 4 years, while, GNP (gross national product) doubles only every 16 years. ${ }^{15}$ That's why now the individual concerns for potency or cost of treatment, and even more precisely, efficacy or safety of a drug is being rationalized as overall risk-benefit ratio on individual level or costaffectivity analysis on the mass scale.

In today's scenario, irrational prescribing has become a global phenomenon ${ }^{20}$ to estimate which, pharmacoepidemiology is the study of the use and effects / side effects of drugs in large numbers of people with the purpose of supporting the rational and cost-effective use of drugs in the population, thereby improving health outcomes. $^{30}$ The basis of pharmacoepidemiological variations can be exogenous like ecological, cultural, food pattern and life style or endogenous like immunity, inborn errors and congenital anomalies. Concerning endogenous problems, incidence and prevalence tend to be used interchangeably. ${ }^{29}$
Most endogenous differences are finally located in genetic make-up (e.g. iatrogenic hemolysis finally being traced to G6PD deficiency). Concerning drug elimination (metabolism as well as excretion), genetic polymorphism is widely known. $^{21}$ These individually inherited differences in drug metabolism such as acetylator status (e.g. sulfonamides and sulfones which require acetylation) play a significant role in determining whether a drug will be hemolytic in G6PD deficient person. ${ }^{2}$ Racial difference in the incidence of iatrogenic hemolysis was established as early as $1952 .{ }^{9}$ Thus G6PD deficiency is known since 5 decades. ${ }^{4}$ Presently $>0.4$ billion people in the world, i.e. $7.5 \%$ of the total human population, show this deficiency. ${ }^{17}$

The enzyme G6PD is also known as NADP $^{+}$ oxidoreductase, (international code EC 1.1.1.49). ${ }^{6}$ Normal G6PD activity is inversely proportional to RBC's age index. Thus hemolytic susceptibility is directly proportional to the RBC aging as G6PD also has a halflife. Contextually RBCs are classified as nascent (reticulocytes), recent (<10 day), juvenile (10-30 days), mature (30-60 days), aged (60-90 days) and senescent $(>$ 100 days) - also denoted by age index I to VI. The 
deleterious effect is not immediate and is initially nullified by the little amount of glutathione already available till the total capacity of antioxidant mechanism is used up.

When G6PD deficiency is relatively mild (as in the class III G6PD $\mathrm{A}_{-}$), the hemolytic anemia is self-limited because only the older RBCs are destroyed and young RBCs/ reticulocytes have normal or near normal enzyme activity $^{2}$ to protect themselves from oxidative stress. Thus hemolysis starts 2-3 days after the administration of the oxidant drug. Young RBCs/ reticulocytes, which are normally $<3 \%$ of total RBC count, have normal or near normal enzyme activity ${ }^{2}$ and their compensatory excess after recent hemolysis can interfere with the screening results. By the same token, this belated start of hemolysis is self-limiting within a week even if the drug is continued further and hemoglobin level returns back to normal by $3^{\text {rd }}-4^{\text {th }}$ week as compensatory production of new reticulocyte cells which are now far more than original " $<3 \%$ " and would not be as much deficient in G6PD. If the G6PD variant is highly defective, even the slightest oxidative stress, as seen in the routine life, is enough to precipitate hemolysis in such case withdrawal of the drug is necessary. In patients with severely deficient forms (e.g. Mediterranean variant), hemolysis continues as long as the administration of drug continues because even the younger RBCs are deficient enough. ${ }^{2}$

Hemolytic anemia after administration of the antimalarial drug primaquine (also known as plasmoquine and plasmochin) was reported as early as $1926 .^{3}$ A long list of drugs thought to cause hemolysis evolved with time. A list of unsafe drugs is given in the Table 1.

\section{Table 1: Drugs and chemicals that should be avoided by persons with G6PD deficiency. ${ }^{2}$}

\begin{tabular}{|ll|}
\hline Acetanilid & $\begin{array}{l}\text { Phenazopyridine } \\
\text { Furazolidone }\end{array}$ \\
(Furoxone) & Phenylhymdrazine \\
Isobutyl nitrite & Primaquine \\
Methylene Blue & Sulfacetamide \\
Nalidixic acid & Sulfamethoxazole \\
(NegGram) & (Gantanol) \\
Naphthalene & Sulfanilamide \\
Niridazole & Sulfapyridine \\
(Ambilhar) & Thiazolesulfone \\
Nitrofurantoin & Toluidine blue \\
(Furadantin) & Trinitrotoluene (TNT) \\
& Urate oxidase 36z \\
\hline
\end{tabular}

Concurrently, ethanol increases the generation of reactive oxygen species in the tissues and its acute intake decreases reduced glutathione levels in plasma and erythrocytes. $^{12}$ Additionally, the ethanol metabolite acetaldehyde inside of the erythrocyte has the ability to generate free radical species and to cause deleterious effects on erythrocytes. $^{27}$
Ethanol, though a reducing agent itself, requiring own oxidation into acetaldehyde, acid and finally $\mathrm{CO}_{2}$ and $\mathrm{H}_{2} \mathrm{O}$ - is a highly potent inhibitor of erythrocyte G6PD enzyme activity in vitro. ${ }^{6}$ Similar many more drugs increasing oxidative stress or inducing hemolysis by another mechanism may add up to hemolytic propensity in G6PD deficient people. While potentially problematic oxidizing drugs furazolidone and nalidixic acid have been deleted from NML-2003 (National Medicine List of India, 2003) onwards; methylene blue, nitrofurantoin, primaquine, sulphacetamide, sulphamethoxazole etc cause hemolysis in people with G6PD deficiency ${ }^{31}$ and still continue in NML-2011 $\left(17^{\text {th }}\right.$ and the latest edition of our National Medicine List). ${ }^{16}$

Plasma level of sulfonamides and sulfones (and thereby severity of hemolysis in G6PD deficiency too) varies also with the person's capacity of metabolic acetylation of the drug. Only a minority of Indian population $\left(<1 / 3^{\text {rd }}\right)$ is known to be fast acetylator. ${ }^{23}$ Thus a slow acetylator with moderate hemolytic tendency can exhibit clinical/ laboratory severity as much as fast acetylator with severe hemolytic tendency. Thus, among G6PD deficient patients taking sulfonamides or sulfones, slow acetylators are more prone to the hemolysis. ${ }^{28}$ Worth special mention are dapsone (an antileprotic sulfone) and another extreme of clandestine use of amyl nitrite for aphrodisiac purposes $^{25}$ inflicting similar hemolysis. But dapsone is never taken OTC (and all the cases of oxidative stress induced hemolysis should be considered essentially iatrogenic).

Dapsone is a deleterious oxidant drug given during already excess free radical stress of leprosy. ${ }^{11}$ In normal persons, dapsone reduces hemoglobin level by $2 \mathrm{gm} \%$ and even in long term therapy, in which anemia and G6PD level is partially compensated by reticulocytosis, hemoglobin remains $1 \mathrm{mg} \%$ less. $^{8}$ That's why dapsone is contraindicated in G6PD deficiency. ${ }^{13}$ But yet any national (like NRLEP) or international (like WHO) body have no clear cut recommendation for screening of G6PD before starting dapsone regime. Neither there is any precaution concerning dapsone considered categorically for G6PD deficiency. Concerning isoniazid, a first line drug against any type of tuberculosis, can be equally problematic if G6PD deficiency is not recognized beforehand and a hemolysis would be more unethical as isoniazid doesn't enjoy the monopoly in tuberculosis treatment as does dapsone in leprosy.

In cases of India, pyridoxine has not be labeled as a 'mandatory' supplement to isoniazid and any neuropathic complain rather prompts the screening of the patient for his or her acetylator status. ${ }^{22}$ The same logic is also applicable for over-the-counter (OTC) oxidative drugs, which are inherently supposed to be safe enough. However, most drugs, whether officially permitted or not, are available in India as OTC and the problem is multiplied many times. Contextually relevant is the plan of the Indian government to sell the OTC drugs through 
post offices in remote rural areas of some selected states like Andhra Pradesh, Maharashtra and Uttarakhand. ${ }^{26}$ In such a setting, government machinery might also be a part of the serious morbid outcome due to different G6PD deficiency pattern. To rule out such a situation in our locality, this study planned to trace the pattern of G6PD deficiency as well as oxidizing drugs in patients attending C U Shah Medical College (CUSMC) Hospital.

The present study aimed at screening of the patients visiting the $\mathrm{C} \mathrm{U}$ Shah Medical College (CUSMC) Hospital, Surendranagar to determine the communitywise prevalence of G6PD (Glucose-6-PhosphateDehydrogenase) deficiency among them and to analyze and evaluate the risks and the consequences of such incidence of G6PD deficiency combined with the use of oxidizing drugs in the area.

\section{METHODS}

Gold standard for measurement of G6PD is the fluorescent spot method. The International Committee for Standardization in Hematology has recommended the fluorescent spot test as a screening test for G-6-PD deficiency ${ }^{10}-100 \%$ sensitivity and $98 \%$ specificity. ${ }^{14}$ Crayman's hemoglobin colorimetric kit (item no 700540) based on fluorescent technique was used. Blood from already collected sample in official EDTA vial of the hospital was centrifuged at $1000 \mathrm{X} \mathrm{g}$ for 10 minutes at $4^{\circ} \mathrm{C}$.

After removing top plasma and buffy coat, sedimented erythrocytes were diluted $1: 1 \mathrm{v} / \mathrm{v}$ with phosphate buffered saline ( $\mathrm{pH}$ 7.4). Ice placed erythrocytes were sonicated for lysis. Lysate was further diluted 1:20 with assay buffer for assaying. The test was carried out at setting of excitation wavelength $535 \mathrm{~nm}$ and emission wavelength $590 \mathrm{~nm}$. G6PD activity $<5 \mu / \mathrm{min} / \mathrm{gm} \mathrm{Hb}$ was labeled as G6PD deficient (Crayman, 2012). The test can rarely yield false negative (no G6PD deficit) in reticulocytosis (as after recent hemolysis) and false positive in severely anemic persons (less count of RBC or amount of $\mathrm{Hb}$ ). ${ }^{7}$

\section{Exclusion criteria}

1. History of recent hemolysis (incidence of smoky black urine within past 15 days) - compensatory transient reticulocytosis can cause higher than usual level of G6PD in these patients giving false negative results. Leukocytes and platelets also have G6PD but due to their negligible count $\left(<11 \times 10^{9} / \mathrm{L}\right.$ and $<5 \times$ $10^{11} / \mathrm{L}$ respectively) compared to $\mathrm{RBCs}\left(6 \times 10^{12} / \mathrm{L}\right)$ - they don't effect the reading significantly.

2. Anemia at the time of the study - Subjects with hemoglobin level $<10 \mathrm{gm} / \mathrm{dL}$ were excluded as their uncompensated inclusion in the study yields erroneous results. $10 \mathrm{gm} / \mathrm{dL}$ of hemoglobin, which also expressed as $10 \mathrm{gm} / 100 \mathrm{ml}$ or $10 \mathrm{gm} \%$, is standardized as the indicators of marked anemia while hemoglobin level between 10 to $11 \mathrm{gm} \%$ indicates only early anemia ${ }^{18,24}$ were included safely in the study.

\section{Study sample}

Anticoagulated (EDTA added) blood was taken from the remnant sample of the patients - sample was collected for some other investigation and no patient was contacted specially for blood sample collection. Thus though the patients were not affected invasively specially for this study, a permission from institutional ethical committee was taken and patient proper consent for related interview was obtained in each case. The patients' personal history (current $\mathrm{Hb}$, recent hemoglobinuria) and demographic data (age, sex, community) were recorded. As highly inbred populations (e.g. maritally isolated/ orthodox society) have more prevalence of genetic anomalies ${ }^{1}$, this study has also enlisted the subjects community-wise.

As the concept of castes isn't coherent socio-legally and there is no unequivocal universally accepted definition of a caste ${ }^{5}$, samples are classified into communities "as orally proclaimed by the subjects". Many patients visiting the hospital get themselves simultaneously registered for different departments (without official cross-reference) but present to laboratory as one entity. In such cases billing number of the laboratory was found to be more unambiguously identifying the subjects. That's why billing numbers were used for patients' identification.

\section{Sampling}

As per national prevalence of G6PD deficiency $(2.5 \%$, prevalence rate $=0.025$ ) reported earlier ${ }^{31}$, with $95 \%$ confidence interval and permitted error of \pm 0.05 , the estimated sample size is 94 for binomial distribution (as G6PD status is noted only as normal or below normal). But permitting a biological variation, more samples were taken.

Post hoc analysis of 10 G6PD deficient cases out of 150 (i.e. $6.6 \%$ ) indicates that for a binomially distributed data, the sample of 150 was near about required (with 95\% confidence interval, prevalence rate 0.066 and permitted error of \pm 0.05 , the estimated sample size is 154). ${ }^{19}$

\section{RESULTS}

After ruling out as per exclusion criteria, the consecutive 150 subjects were distributed in 15 communities as per Table 2 and Figure 1. Genderwise, males (being heterozygous for the x-linked character of G6PD status) were expected ly more (1.5 times, 6 male cases compared to 4 female) prone as shown in Figure 2.

Hemoglobin levels in the normal and G6PD deficient males were found to be $12.286(\sigma=0.84)$ and $11.716(\sigma$ $=0.96$ ) respectively as shown in Table 3 and Figure 3 . Hemoglobin levels in the normal and G6PD deficient 
females were found to be $10.523(\sigma=0.39)$ and $10.6(\sigma=$ $0.28)$ respectively as shown in the same Table 3 and
Figure 3.

Table 2: Community-wise distribution of visitors to the laboratory and incidence of G6PD deficiency in them.

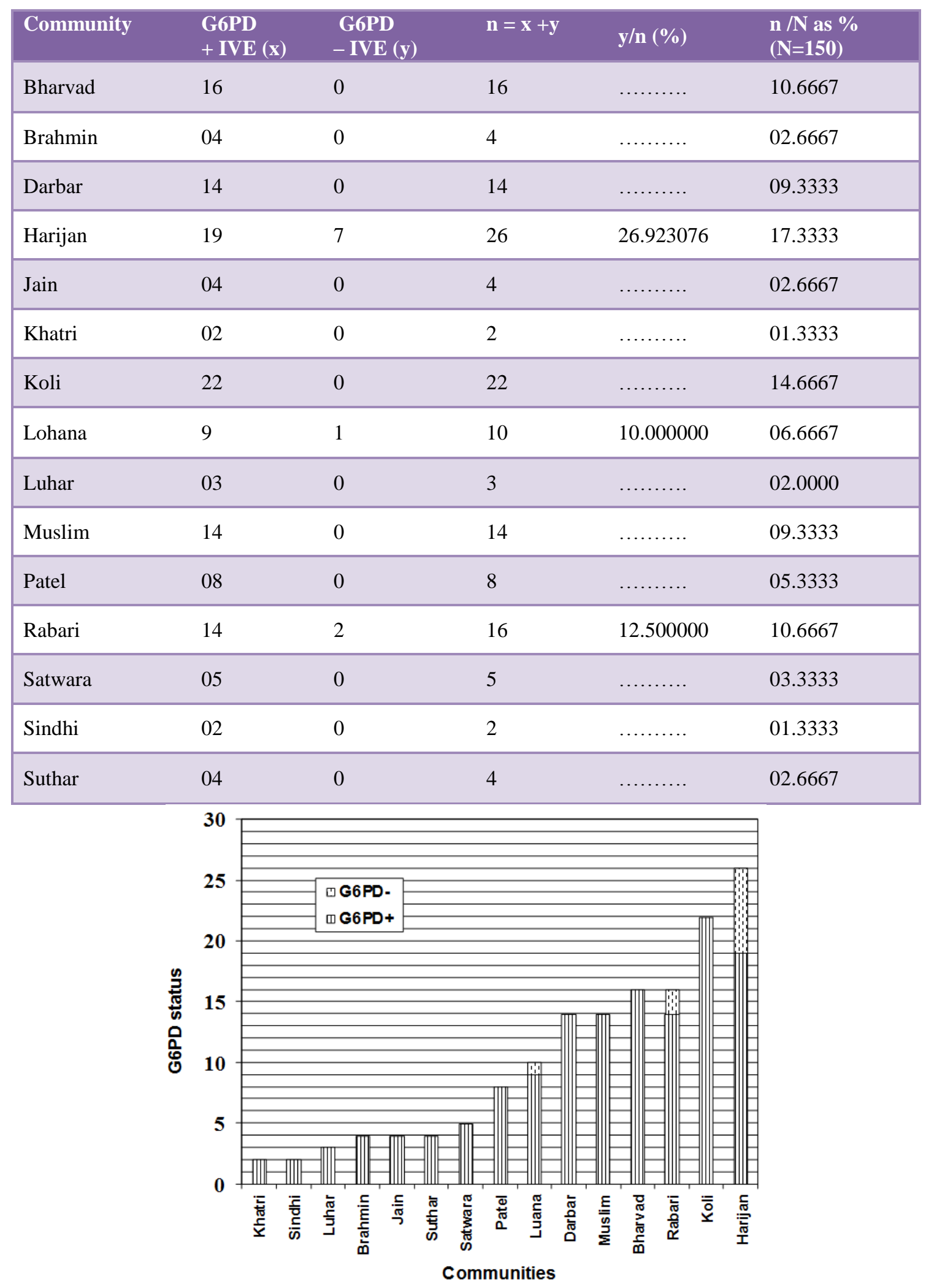

Figure 1: Incidence of G6PD Deficiency in the visitors of CUSMC hospital, Surendranagar. 
Table 3: Distribution of gender, G6PD status, age and Hb level. $(\sigma=$ standard deviation)

\begin{tabular}{|lllll|}
\hline $\begin{array}{l}\text { Mean } \\
\text { Values }\end{array}$ & $\begin{array}{l}\text { Normal } \\
\text { Male (78) }\end{array}$ & $\begin{array}{l}\text { G6PD } \downarrow \\
\text { Male (6) }\end{array}$ & Normal Female (62) & $\begin{array}{l}\text { G6PD } \downarrow \\
\text { Female (4) }\end{array}$ \\
\hline $\mathrm{Hb}(\mathrm{gm} / \mathrm{dL})$ & 12.286 & 11.716 & 10.523 & 10.6 \\
& $(\sigma=0.84)$ & $(\sigma=0.96)$ & $(\sigma=0.39)$ & $(\sigma=0.28)$ \\
\hline \multirow{2}{*}{ Age } & 36.744 & 36 & 34.113 & 32.75 \\
& $(\sigma=21.03)$ & $(\sigma=21.70)$ & $(\sigma=18.21)$ & $(\sigma=19.87)$ \\
\hline
\end{tabular}

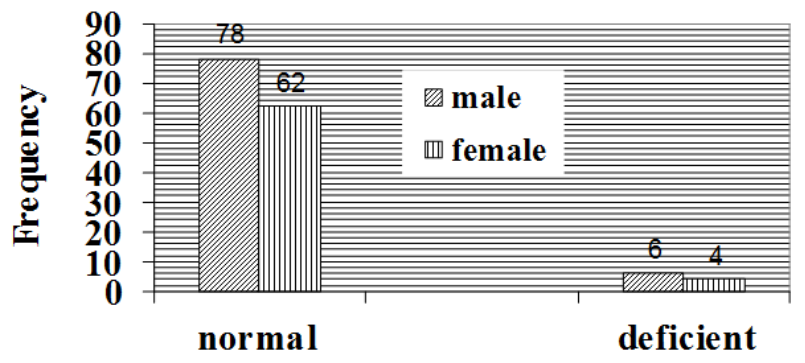

G6PD status

Figure 2: Gender-wise distribution of G6PD deficiency.

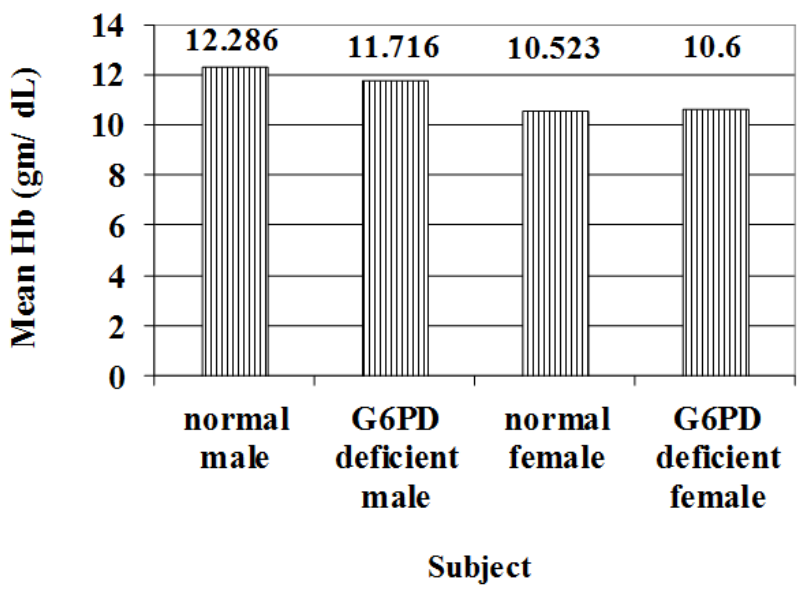

Figure 3: Gender-wise distribution of $\mathrm{Hb}$ in normal \& G6PD deficient population.

Mean age of the normal and G6PD deficient males were found to be $36.744(\sigma=21.03)$ years and $36(\sigma=21.70)$ years while mean age of the normal and G6PD deficient females were found to be $34.113(\sigma=18.21)$ years and $32.75(\sigma=19.87)$ as shown in Table 3 and Figure 4.

In the tested 150 samples, Harijans are found to have maximum G6PD negative status -3 females and 4 males (total 7) out of 26 i.e. $27 \%$. Other communities screened lower for G6PD are Rabari (1 male and 1 female out of 16 i.e. $12.50 \%$ ) and Lohana (1 male out of 10 i.e. $10 \%$ ). Thus out of 150, 78 males and 62 females were normal while 6 males and 4 females were G6PD deficient.

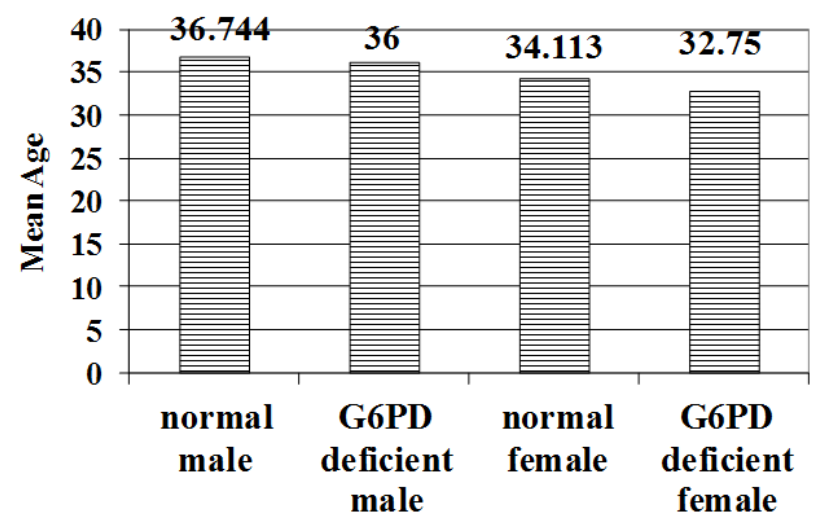

Subjects

Figure 4: Age-wise distribution of G6PD Deficiency in the studied population.

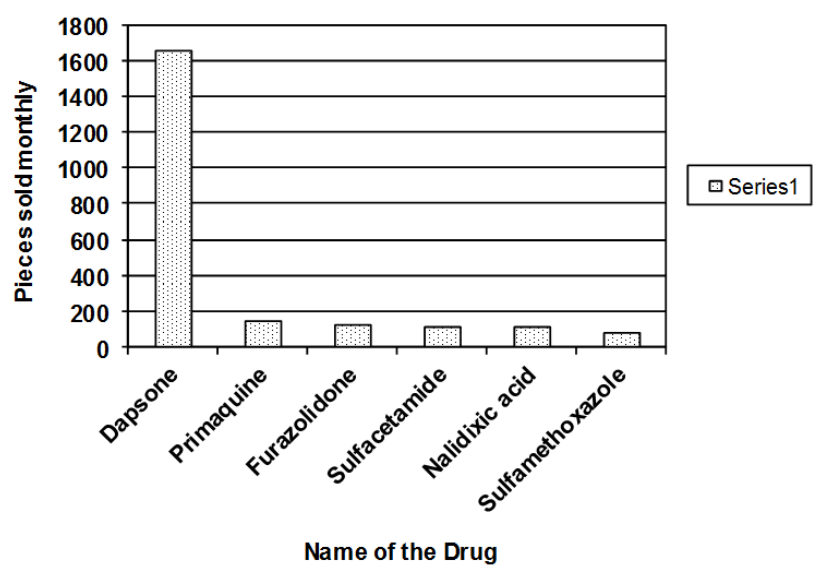

Figure 5: Sale pattern of the drugs inducing hemolysis in the G6PD deficient patients at the institutional pharmacy store, C U Shah Medical College and Hospital Surendranagar.

Pharmacy: Out of the potentially dangerous drugs enlisted in Table 1, only 6 drugs were traced in the monthly sale of 98,872 pieces (tablets/ capsules/ ampoules) as shown in Table 4 and Figure 5. The 6 drugs are dapsone (1650), primaquine (138), furazolidone (114), sulfacetamide (112), nalidixic acid (109), sulfamethoxazole (73) - number of pieces of drugs sold in the given month shown in the following parentheses. 
Table 4: One month sale of the drugs inducing hemolysis in the G6PD deficient patients at the institutional pharmacy store, C U Shah Medical College Hospital, Surendranagar.

\begin{tabular}{|lll|}
\hline Sr. No. & Drug & Pieces \\
\hline 1 & Dapsone & 1650 \\
\hline 2 & Primaquine & 138 \\
\hline 3 & Furazolidone & 114 \\
\hline 4 & Sulfacetamide & 112 \\
\hline 5 & Nalidixic acid & 109 \\
\hline 6 & Sulfamethoxazole & 73 \\
\hline
\end{tabular}

\section{DISCUSSION}

Harijans form the largest hospital visitor group i.e. $>1 / 6$ (26 out of 150) and also screen for the highest incidence 7 deficient in G6PD activity. Other than Harijan, Rabari and Lohana - none of the 12 remaining communities yielded any G6PD deficient case. Bharvad (16), Darbar (14) and Koli (22), if taken together, form more than one third $(34.66 \%)$ of the sample but exhibit no G6PD deficiency.

Over-representation of Harijan community might be a reason that the whole sample has higher incidence of G6PD deficiency - 10 out of 150 i.e. $6.66 \%$ - compared to recent national incidence rate of $2.5 \%{ }^{31}$. To the contrary, under represented other communities might be not being that free from G6PD deficiency as elicited here.

As per the sale from the institutional pharmacy store in the last month (October, 2008), these all oxidizing OTC drugs are scarcely prescribed (2096 out of a total of 98,872 pieces 2196 only i.e. $<2.22 \%$ ). Among widely used oxidizing drugs dangerous for G6PD deficient patients, dapsone (1650) is the most common.

Primaquine (138), Sulfacetamide (112) and Nalidixic acid (109) are the next three widest used drugs. Furazolidone is sold in combination with loperamide, norfloxacin or tinidazole. Sulfamethoxazole is sold in combination with trimethoprim (generic name cotrimoxazole).

Furazolidone (114) and Sulfamethoxazole (73) are limited to combinations with other drugs. Such combination can affect the oxidizing potential of the two drugs. Except dapsone, which is still least substituted by newer alternatives, the reason of the limited use of these potentially hazardous drugs might be awareness about better or newer alternatives. Pharmaceutical promotions of newer entities can be an additional factor.

Yet, seeing $6.66 \%$ rate of G6PD deficiency in the present study, the total supply of 2196 pieces of these drugs (which could be substituted by alternatives) per month can induce $(2196 \times 6.66 \%=) 146$ incidences a month i.e. around 5 hemolysis a day by the most. A real figure of hemolysis could to be different - reasons behind might be a) The prevalent mode of administration of the oxidizing drug. For example, sulfacetamide supply from the institutional pharmacy store is limited to eye/ear drops - hardly absorbed systemically enough to induce hemolysis.

b) Some initial doses of oxidizing drug can be tackled even by the little glutathione available in G6PD deficient population. Contrarily, additional oxidizing stress (like other disease or drug) or hemolytic propensity (like alcoholism ${ }^{6}$ ) can increase the morbidity.

\section{CONCLUSION}

The incidence of G6PD deficiency in the present study is $6.66 \%$ (10 out of 150). In the tested 150 samples, Harijans are found to be maximally G6PD deficient -3 females and 4 males (total 7) out of 26 (i.e. 27\%). Other communities screened negative for G6PD are Rabari (1 male out of 7 males and 1 female out of 9 females) and Lohana ( 1 male out of 2 males - out of 8 females, none was screened negative).

Most common visitors of the hospital are from the Harijan community (26) followed by Koli (22), Bharvad (16), Rabari (16), Darbar (14), Muslim (14), Lohana (10), Patel (08), Satwara (05), Suthar (04), Brahmin (04), Jain (04), Luhar (03), Khatri (02) and Sindhi (02). Age or hemoglobin level is not significantly different among normal and G6PD deficient persons (within one standard deviation).

While applying oxidizing drugs in a person of Harijan community (prevalence 7 out of total 26, i.e. 27\%), extra caution is required, esp. if a person if otherwise vulnerable (e.g. alcoholic). For other less represented communities, larger stratified sampling is required.

Funding: No funding sources

Competing interests: None declared

Ethical approval: The study was approved by the Institutional Ethics Committee

\section{REFERENCES}

1. Babbitt GA. Inbreeding reduces power-law scaling in the distribution of fluctuating asymmetry: an explanation of the basis of developmental instability. Heredity 2006;97:258-68.

2. Beutler E. G6PD deficiency. Blood 1994;84:361336.

3. Beutler E, Duparc S; G6PD Deficiency Working Group. Glucose-6-Phosphate Dehydrogenase Deficiency and Antimalarial Drug Development. Am J Trop Med Hyg 2007;77:779-89.

4. Beutler E. Glucose-6-phosphate dehydrogenase deficiency: a historical perspective Blood 2008;111:16-24.

5. Bulletin of the Bihar Tribal Research Institute 1965;5:12. 
6. Buyukokurogle ME, Altikat S, Ciftci M. The Effect of ethanol on Glucose 6-Phosphate Dehydrogenase Enzyme Activity from Human Erythrocyte in vitro and Rat Erythrocyte in vivo. Alcohol Alcohol 2002;37:327-9.

7. Dacie JV, Lewis SM. Practical Hematology, 9th Ed. Edinburgh: Churchill Livingstone; 2001.

8. Fredberg IM, Eisa AZ, Wolf K, editors. Fitzpatrick: Dermatology in general medicine. 5th. New York: McGraw-Hill; 1999. pp. 2791-2.

9. Hockwald RS, Arnold J, Clayman CB, Aling AS; Status of Primaquine : Toxicity of Primaquine in Nigros. JAMA 1952:149:1568.

10. Tantular IS, Kawamoto F. An improved, simple screening method for detection of glucose-6phosphate dehydrogenase deficiency. Trop Med Int Health 2003;8:569-74.

11. Jyothi P, Riyaz N, Nanadkumar G, Binitha MP. A Study of Oxidative Stress in Paucibacillary and Multibacillary Leprosy. Ind J Dermatol Venereol Leprol 2008;74:80.

12. Loguercio C, Clot P, Albano E, Argenzio F, Grella A, De Girolamo V, et al. Free radicals and not acetaldehyde influence the circulating levels of glutathione after acute or chronic alcohol abuse: in vivo and in vitro studies. Ital $\mathbf{J}$ Gastroenterol Hepatol 1997;29:168-73.

13. Mandell GL, Bennett JE, Dolin R, editors. Mandell, Douglas, and Bennett's principles and practice of infectious diseases. 5th ed. New York: Elsevier/Churchill Livingstone; 2005. p. 523.

14. Markic J, Krželj V, Markotić A, Marušić E, Stričević L, Zanchi J, Bošnjak N, Sapunar A. High Incidence of Glucose-6-phosphate Dehydrogenase Deficiency in Croatian Island Isolate: Example from Vis Island, Croatia. Croat Med J 2006;47:566-70.

15. Melrose D. Double deprivation public and private drug distribution from the perspective of the third world's poor. World Dev 1983;11:181-6.

16. National Medicine List of India - 2011. Available at http://ebookbrowse.com/list-of-essential-medicineindia-pdf-d312718262. Accessed 16 January 2013.

17. Noori-Daloii MR. M. Daneshpajooh. Molecular basis of g6pd deficiency: current status and its perspective. Acta Medica Iranica 2008;46:167-182.

18. Park K. Park's Textbook of Preventive and Social Medicine. 19th ed. Jabalpur: M/s Banarasidas Bhanot Publishers; 2007.
19. Program for Sample Size Estimation. Available at http://www.stattools.net/SSizprop_Pgm.php. Accessed 20 January 2013.

20. Rehan HS, Singh C, Tripathi CD, Kela AK. Study of drug utilization pattern in dental OPD at tertiary care teaching hospital. Indian $J$ Dent Res 2001;12:51-6.

21. Relling MV, Giacomini KM. Pharmacogenetics. In: Brenton LL, Lazo JS, Parker KL, editors. Goodman \& Gilman's. The pharmacological basis of therapeutics, 12th ed. New York: McGraw Hill; 2011:145-68.

22. Sahasrabudhe T. Is Supplementation of Pyridoxine A Necessary Adjunct with Daily First Line TB Chemotherapy Regimen for Indian Patients? Res J Pharm Biological Chemical Sci 2012;3:1042.

23. Singh N, Dubey S, Chinnaraj S, Golani A, Maitra A. Study of NAT2 gene polymorphisms in an Indian population: Their association with plasma isoniazid concentration in a cohort of tuberculosis patients. Molecular Diagnosis and Therapy 2009;13:49-58.

24. Sood SK, Rusia U. Annals of National Academy of Medical Sciences India 1986;22:235.

25. Stalnikowicz R, Amitai Y, Bentur Y. Aphrodisiac Drug-Induced Hemolysis. J Toxicol Clin Toxicol 2004;42:313-6.

26. The Economic Times, 17/03/2008.

27. Tyulina OV, Huentelman MJ, Prokopieva VD, Boldyrev AA, Johnson P. Does ethanol metabolism affect erythrocyte hemolysis? Biochim Biophys Acta 2000;1535:69-77.

28. Vallely A, Vallely L, Changalucha J, Greenwood B, Chandramohan D. Intermittent preventive treatment for malaria in pregnancy in Africa: What's new, what's needed? Malar J 2007;6:16.

29. World Health Organization. Surveillance standards for antimicrobial resistance, WHO/CDS/CSR/DRS/2001/5. Available at http://www.who.int/drugresistance/publications/WH O_CDS_CSR_DRS_2001_5/en/. Accessed 20 January 2013.

30. World Health Organization. Introduction to drug utilization research. Geneva: World Health Organization; 2003.

31. Lee R, Foerster J, Lukens J, Paraskevas F, Greer J, Rodgers G. Wintrobe's clinical hematology, 10th ed. Baltimore: Lippincott Williams \& Wilkins; 1999:1176-90.

doi:10.5455/2319-2003.ijbcp20130310

Cite this article as: Pathak RR, Chhaiya SB, Mehta DS. Prevalence of G6PD deficiency versus oxidizing drugs: a survey in the tertiary care hospital. Int J Basic Clin Pharmacol 2013;2:170-6. 